\title{
Effect of Ozonation Time on the Clarification of Juice of Sugarcane Varieties
}

\author{
Marilisa Flávia Pereira Di-Tanno, ${ }^{1, *}$, Dora Inês Kozusny-Andreani ${ }^{1}$, Maria Teresa Mendes Ribeiro \\ Borges $^{2}$, Alessandra de Lourdes Ballaris ${ }^{1}$, Renato Amaro Zângaro ${ }^{3,4}$ \\ ${ }^{1}$ Universidade Brasil, Campus of Fernandópolis, Fernandópolis, São Paulo, Brazil. \\ ${ }^{2}$ Federal University of São Carlos, Center of Agricultural Sciences, Araras, São Paulo, Brazil. \\ ${ }^{3}$ Universidade Anhembi Morumbi, São José dos Campos, São Paulo, Brazil. \\ ${ }^{4}$ Center of Innovation, Technology and Education (CITE), São José dos Campos, São Paulo, Brazil.
}

\begin{abstract}
How to cite this paper: Marilisa Flávia Pereira Di-Tanno, Dora Inês Kozusny-Andreani, Maria Teresa Mendes Ribeiro Borges, Alessandra de Lourdes Ballaris1, Renato Amaro Zângaro. (2021) Effect of Ozonation Time on the Clarification of Juice of Sugarcane Varieties. International Journal of the Science of Food and Agriculture, 5(1), 199-209.

DOI: 10.26855/ijfsa.2021.03.026
\end{abstract}

Received: February 6, 2021

Accepted: March 5, 2021

Published: March 31, 2021

*Corresponding author: Marilisa Flávia Pereira Di-Tanno, Universidade Brasil, Campus of Fernandópolis, Fernandópolis, São Paulo, Brazil.

Email: mditanno@hotmail.com

\begin{abstract}
The process of sugar clarification has been the subject of several studies in order to improve the quality of the obtained sugar both from the point of view of new technologies of equipment and processes and regarding the study of physicochemical properties and reduction of residues in sucrose during the clarification process. The aim of this study was to characterize some physicochemical properties of sugarcane juice when clarified with ozone during different ozonation times. Three tests were carried out using the juice extracted from the sugarcane varieties RB 867515, RB 855453, and SP 891115. The following technological variables were analyzed: $\mathrm{pH}$, acidity, ICUMSA color, reducing sugars (RS), total soluble solids (Brix\%), polarization (Pol\%), and sugarcane juice. The physicochemical characteristics of the sugarcane juice were influenced by the ozonation time and crop variety. An average reduction of $77 \%$ was observed in the color without changing significantly the content of TSS and Pol\%. However, changes were observed in the $\mathrm{pH}$, acidity, and reducing sugars. The variables that most contributed to explaining the dynamics of sugarcane juices as a function of ozonation time in the three varieties under study were $\mathrm{pH}$, color, acidity, and air.
\end{abstract}

\section{Keywords}

Clarification, Physicochemical parameters of sugarcane juice

\section{Introduction}

Brazil stands out as the world's largest producer of sugarcane (Saccharum spp.) with a production of 646 million tons [1]. The harvested area is estimated at 8.77 million hectares, distributed in all producing states, being the State of São Paulo the largest producer, accounting for $54 \%$ of the processed sugarcane. Sugar production is expected to reach 39.39 million tons and the expectation of total ethanol production is 26.12 billion liters [1]. Thus, changes in the sugar-energy sector, whether in crop management or in product processing techniques, can significantly affect Brazilian production.

For the production of white refined sugar, sulfur dioxide or sulfite is commonly used in the mills in the treatment for the clarification of the sugarcane juice. This process is called sulfitation or sulfo-defecation, and the efficiency of this process is directly associated with the final product quality [2].

According to Sartori et al. [3], sulfitation is an environmental contaminant process by the action of sulfur dioxide and has been criticized for promoting the formation of residual sulfur compounds (TRS) in sugar, being contraindicated for human respiratory health. In addition, infants and persons with reduced activity of the sulfite oxidase enzyme may present severe neurological disorders caused by toxic reactions through the accumulation of sulfite in the body [4].

Although regulated as an additive and the widespread use of sulfites in the food industry, innumerable other adverse effects to human health are being associated with this practice, such as anaphylaxis, urticaria, angioedema, hypotension, 
nausea, local gastric irritation from the formation of sulfurous acid, headaches, behavioral disorder and hyperactivity in children, rashes, and diarrhea. Most intolerance reactions take the form of asthmatic attacks and urticaria, along with a feeling of throat discomfort, chest congestion, cough, and hypotension [2, 3, 4, 5].

However, although the use of sulfite as a food additive is regulated by the competent agencies in Brazil, the European Union, and the United States, there is a restriction to the final product in which sulfur dioxide has been used even below the limit of $15 \mathrm{mg} \mathrm{kg}^{-1}$ considered as tolerable. This has led to a decline in exports of Brazilian refined sugar through the adoption of a technical barrier, supported by the legitimacy of food security [2].

In this context, new processes have been proposed in place of the use of sulfur for producing white crystal sugar [3]. Among these processes is the advanced oxidation process (AOP), such as the ozone $\left(\mathrm{O}_{3}\right)$ and hydrogen peroxide $\left(\mathrm{H}_{2} \mathrm{O}_{2}\right)$, which are already used in different sectors of the food industry $[3,6,7]$.

The ozonation process does not generate residues and the air around us is the raw material used, which is a viable alternative. However, more studies are needed to determine the best processing conditions since little is known on the physicochemical quality of the sugarcane juice obtained after ozonation [7].

The sugarcane industry in the State of São Paulo considers that the sugarcane to be industrialized must have, among other characteristics, a juice containing at least $18{ }^{\circ}$ Brix, i.e. $18 \%$ soluble solids [8], and present a Pol\% ranging from 14.4 (beginning of the season) to 15.3 (during the season) to be considered as mature. These indices are considered as the necessary maturation point for the industrialization of both plant and ratoon sugarcane crop [9]. In addition, the appropriate $\mathrm{pH}$ is also a very important factor since it is associated with the sucrose content. A pH below that appropriate leads to a sucrose hydrolysis, followed by an increase in the juice temperature, leading to the need for an immediate correction with calcium hydroxide addition [10].

In addition to sucrose, the glucose, fructose, and other less important non-sugar compounds participate in the fraction of sugars in sugarcane juice. Reducing sugars (glucose and fructose) are precursors of color in the industrial sugar process, i.e., they participate in color formation reactions depreciating their quality [8]. Moreover, the removal of the color of the sugarcane juice varies according to the variety under study, being influenced by chlorophyll and other chromogenic substances [11], as well as ozone dosage [7].

Given Brazil's significant role in the competitive sugar market worldwide, investments in new technologies are necessary to obtain a better quality product at a lower cost, aiming at the environmental sustainability of the sector. In this context, the aim of this study was to assess the physicochemical characteristics of the juice of the sugarcane varieties RB 867513, RB 855453, and SP 891115 submitted to different periods of exposure to ozone for clarification during the white refined sugar production process.

\section{Methods}

Three tests were carried out using the juice extracted from the sugarcane varieties RB 867515, RB 855453, and SP 891115 (Table 1). The varieties were cultivated in the experimental field of the Federal University of São Carlos (UFSCar), Campus of Araras, SP, Brazil. This study was carried out in the Laboratory of Analysis and Technological Simulation (LAST) of the Department of Agroindustrial Technology and Rural Socioeconomics of the Center of Agricultural Sciences of UFSCar.

Table 1. Agronomic characteristics of the varieties under study

\begin{tabular}{ll}
\hline Variety & General characteristics \\
\hline RB867515 & $\begin{array}{l}\text { High yield, fast development, erect growth habit and easy leaf removal, medium tillering, medium } \\
\text { interrow closing, late maturation and medium-thick stem diameter, good budding ability, high sucrose } \\
\text { content, and medium fiber content. }\end{array}$ \\
High yield, fast growth, high clumping, regular growth rate, medium-late maturation, easy leaf remov- \\
al, erect growth habit, good interrow closing, erect stems of medium diameter, very high sucrose con- \\
tent, and medium fiber content. \\
High yield, very good ratoon budding, medium tillering, late maturation, medium leaf removal, se- \\
mierect growth habit, frequent flowering, high sucrose content, and low fiber content.
\end{tabular}

Source: Ridesa [12], Copersucar [13].

The juices were extracted by disintegration in a forage machine followed by pressings in Codistil-Dedine hydraulic press until obtaining $10 \mathrm{~L}$. The obtained juices were sieved (100 mesh), fractionated into homogeneous parts, subdivided in opaque polypropylene bottles, and submitted to treatments with different ozonation times $(0,2,4,8,16,32,70$, and 100 minutes). The tests for sugarcane juice clarification by ozonation were performed with an Ozon \& Life gaseous 
ozone generating equipment (O\&L 3.0 RM model, São José dos Campos, SP, Brazil) at a flow rate of $28 \mathrm{mg}$ O3 L-1 at an inlet of $1 \mathrm{~L} \mathrm{O} 2 \mathrm{~min}-1$ from a cylinder.

The ozone produced by the generator was coupled with a silicone hose to a hole located in the bottom of a PVC beaker $(1,000 \mathrm{~mL})$, where a porous stainless steel diffuser was adapted to increase the mass transfer of gas to the liquid medium (Figure 1). A silicone hose cut into a half-cane shape was inserted at the top of the beaker and used to seal the edges and support an inverted Buchner funnel. The funnel was coupled to a silicone hose aiming at evacuating the unused ozone to the area outside the laboratory. In contact with the external air, the ozone recombines quickly, turning into $\mathrm{O}_{2}$.

An amount of $200 \mathrm{~mL}$ of juice from each variety was added to different 1,000-mL PVC beakers previously cleaned and sanitized with ozonated water and $70 \%$ alcohol. Subsequently, these juices were submitted to ozonation during 2, 4, $8,16,32,70$, and 100 minutes for determining the physicochemical characteristics $\mathrm{pH}$, titratable total acidity, ICUMSA color, reducing sugars (RS), total soluble solids ( ${ }^{\circ}$ Brix), and polarization (Pol\%). These characteristics were also assessed before the ozonation process, i.e. at the time zero $(0 \mathrm{~min})$.

The $\mathrm{O}_{3}$ concentration was calculated from the $\mathrm{O}_{2}$ inlet into the equipment and multiplied by the exposure time. They were then packed in polypropylene flasks and frozen at $-18 \pm 2{ }^{\circ} \mathrm{C}$ until the analyses were performed. At the time of the physicochemical analysis, the juices were thawed at ambient temperature $\left( \pm 28^{\circ} \mathrm{C}\right)$ for further analysis. All methodologies used for the analyses followed the recommendations of the International Commission for Uniform Methods of Sugar Analysis 2011 (ICUMSA).

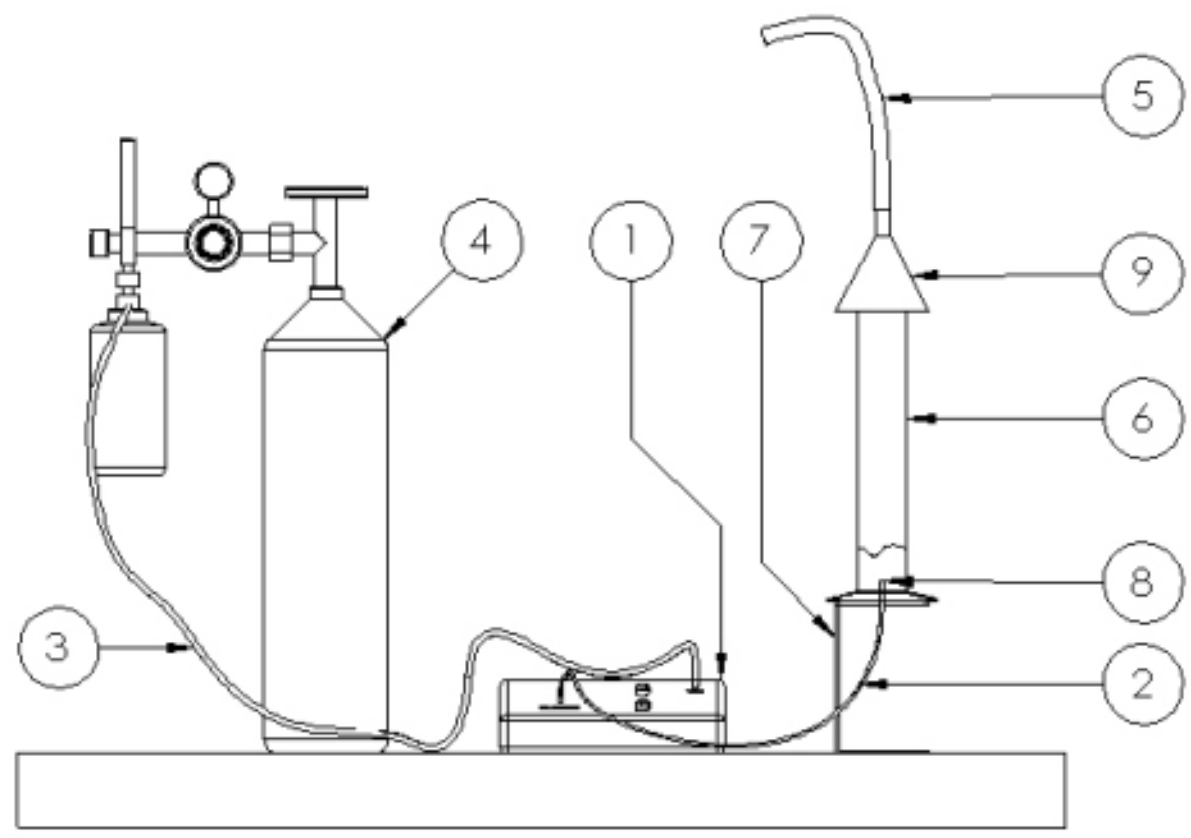

Figure 1. Representation of the ozonation process of the sugarcane juice. Ozone generator (1), ozone inlet into the bottom of the test tube (2), oxygen inlet into the generator (3), oxygen cylinders (4), evacuation of excess gas (5), beaker (6), brackets (7), ozone diffuser in the juice (8), and sealing funnel (9).

The experimental design was a completely randomized design with three replications for both in natura and $\mathrm{O}_{3}$ clarified sugarcane juices. The basic assumptions of the analysis of variance and regression analysis, error normality and variance homogeneity were tested for all the assessed variables. The regression analyses between variables were performed using the software SAS (SAS version 9, SAS Institute, Cary, NC, USA).

The analyzed variables as a function of varieties were submitted to the multivariate exploratory analysis of principal components. The principal component analysis (PCA) is an exploratory multivariate technique that condenses the information contained in a set of original variables into a smaller set consisting of new latent variables, preserving the relevant quantity of the original information. The new variables are the eigenvectors (principal components) generated by linear combinations of the original variables constructed with the eigenvalues of the covariance matrix [13].

The principal components whose eigenvalues were higher than unity were considered in the analysis, according to the criterion established by Kaiser [14]. The coefficients of linear functions, which define the principal components, were used for interpreting their meaning by using the signal and relative size of coefficients as an indication of the weight to be assigned for each variable. Only coefficients with high values were considered for the interpretation, usually those higher than or equal to 0.50 in absolute value. For the analysis, only variables that did not present collinearity were se- 
lected. After selecting and standardizing the variables (zero mean and unit variance), the analysis was processed in the software Statistica 7.0 (StatSoft, Inc., Tulsa, OK, USA).

\section{Results}

\subsection{Univariate relationship between varieties and ozonation time}

Figure 2a shows the $\mathrm{pH}$ behavior of the sugarcane juice as a function of ozonation time. The models were significant $(\mathrm{p}<0.05)$ for all varieties under study. For the variety RB 867515, a quadratic model was adjusted (R2adjusted $=0.98 ; \mathrm{p}$ $=0.004$ ), indicating that $98 \%$ of the $\mathrm{pH}$ variation can be explained by the exposure time. For this variety, the $\mathrm{pH}$ decreased during the initial periods but increased after 70 min (Figure 2a).

However, for the varieties RB 855453 (R2adjusted $=0.80 ; \mathrm{p}=0.002$ ) and SP 891115 (R2adjusted $=0.88 ; \mathrm{p}=$ 0.0001), the adjusted models were decreasing linear, i.e. a gradual decreasing of the $\mathrm{pH}$ values was observed over the ozonation time. Before ozonation exposure, the pH values ranged from 5.1 (RB 855453) and 5.2 (RB 867515 and SP 891115). However, at the end of the ozonation period (100 min), the values decreased to 4.0, 3.3, and 2.9 for the juice of the sugarcane varieties RB 867515, RB 855453, and SP 891115, respectively.

For the variable acidity, the models were also significant $(\mathrm{p}<0.05)$ for all varieties, being adjusted increasing linear models for RB 867515 (R2adjusted $=0.98 ; \mathrm{p}=0.0001$ ), RB 855453 and SP 891115 (R2adjusted $=0.97 ; \mathrm{p}=0.0001$ ) (Figure 2b). The positive relationship observed for the acidity of the sugarcane juice as a function of the ozonation time is the result of the observed relationship when the $\mathrm{pH}$ was assessed under the same condition (Figure 2a).

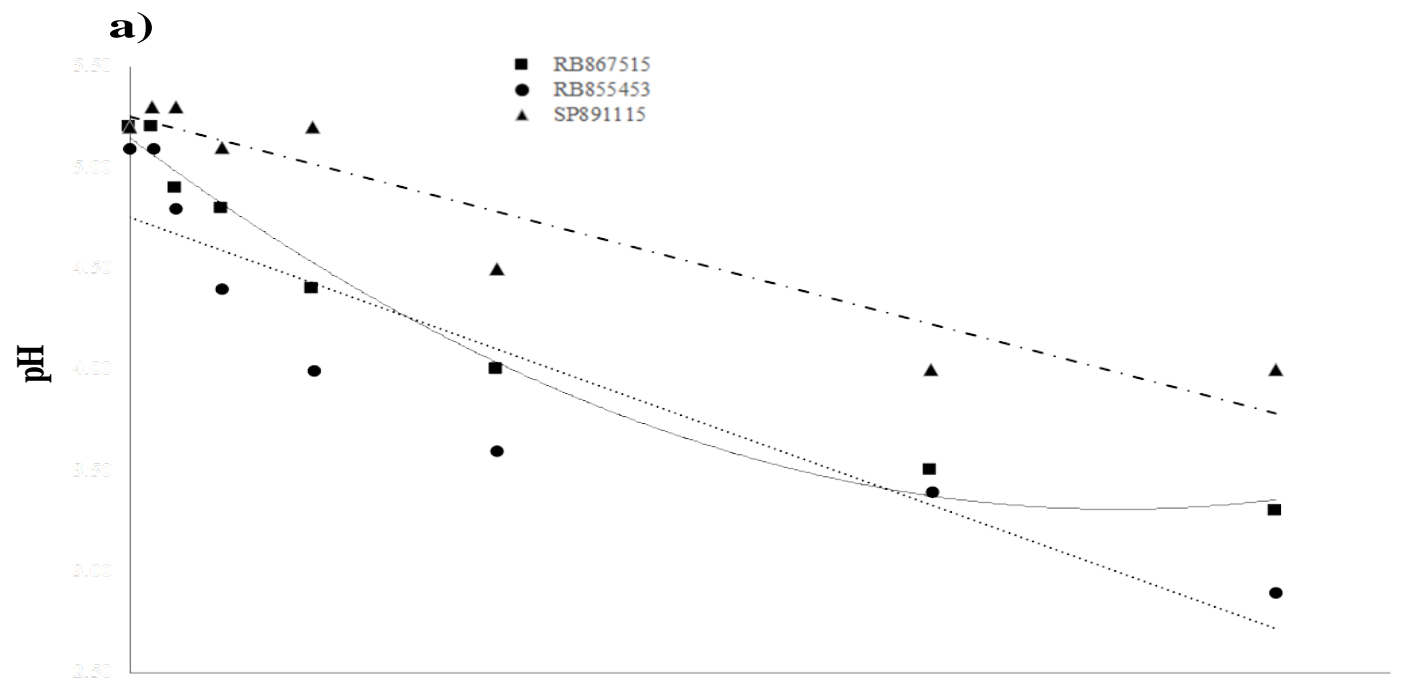

b)

Ozonation time (min)

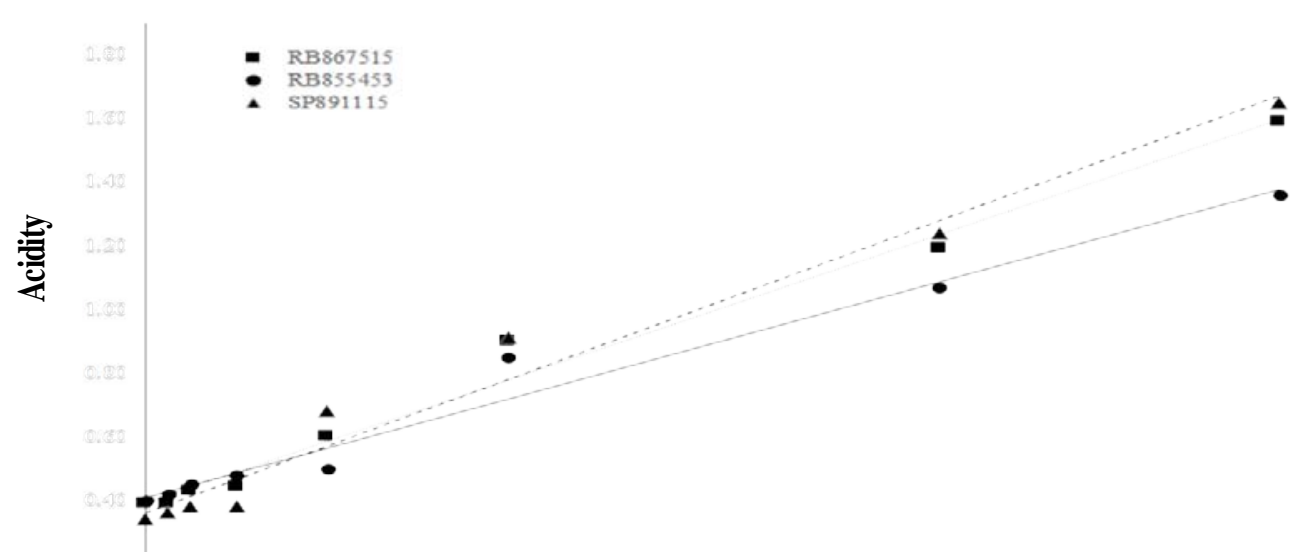

Ozonation time (min)

Figure 2. Regression analysis for $\mathrm{pH}$ (a) and acidity (b) of the juice as a function of the ozonation time for the varieties RB 867515, RB 855453, and SP 891115. 
Regarding the juice color as a function of exposure time, a significant effect $(\mathrm{p}<0.05)$ was observed only for the variables RB 867515 (R2adjusted $=0.95 ; \mathrm{p}=0.05$ ) and RB 855453 (R2adjusted $=0.83 ; \mathrm{p}=0.03$ ), with a quadratic model adjusted for both (Figure 3). Therefore, this is a decreasing relationship, i.e. the ICUMSA color index decreases until the time of $32 \mathrm{~min}$, but from 70 minutes, this behavior changes possibly tending to stabilize. However, a higher exposure time for this index is necessary to confirm this hypothesis (Figure 3).

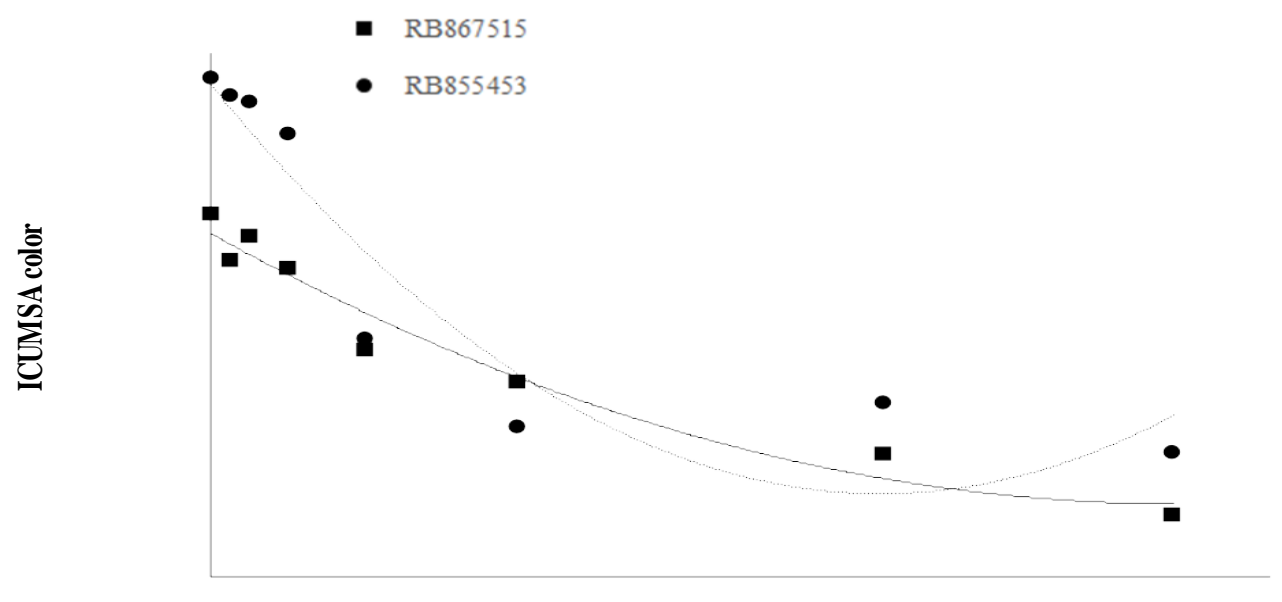

Ozonation time (min)

Figure 3. Regression analysis for the ICUMSA color as a function of the ozonation time for the varieties RB867515 and RB855453.

A significant effect was observed for the reducing sugar of juices of the varieties RB 855453 (R2adjusted $=0.81 ; \mathrm{p}=$ 0.03 ) and SP 891115 (R2adjusted $=0.94 ; \mathrm{p}=0.0001$ ), being adjusted a quadratic model for RB 855453 and a linear model for SP 891115 (Figure 4). Thus, the RS from the juice of the variety RB 855453 increased in the initial period of exposure up to $32 \mathrm{~min}$ but decreased from $70 \mathrm{~min}$ of ozonation (Figure 4). In the analysis of the variety SP 891115, a different behavior was observed. In this case, RS increased throughout the exposure period, indicating that $94 \%$ of the variation of this attribute occurs due to the period of exposure to the ozone gas.

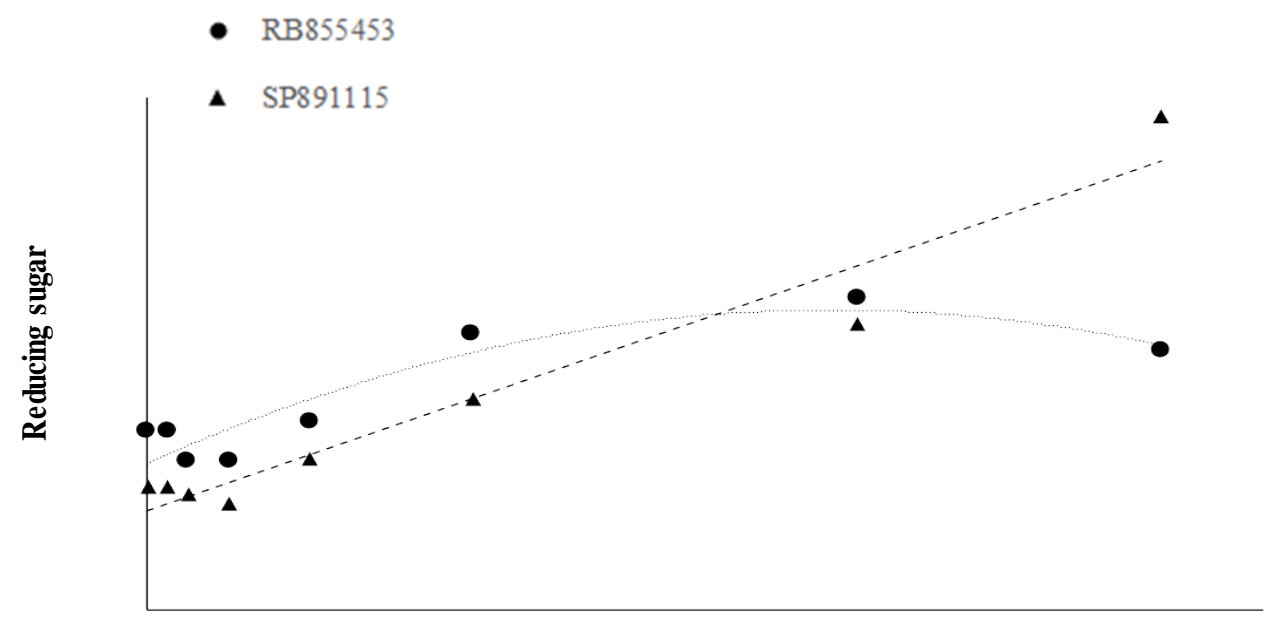

\section{Ozonation time (min)}

Figure 4. Regression analysis for the reducing sugar as a function of the ozonation time for the varieties RB855453 and SP891115.

In relation to Pol (\%), only the variety SP 891115 was adjusted to a significant regression model (R2adjusted $=0.75$; $p=0.01$ ), indicating that $75 \%$ of the variation of Pol (\%) can be explained by the period of exposure to ozone. The cubic model indicates three changes in the behavior of this variety as a function of the ozonation time. First, a decreasing behavior, i.e. Pol (\%) decreased with ozonation until $16 \mathrm{~min}$ of exposure and then, in the range from 32 to $70 \mathrm{~min}$, Pol (\%) increased and decreased again until the end of the assessment period (100 min) (Figure 5). 


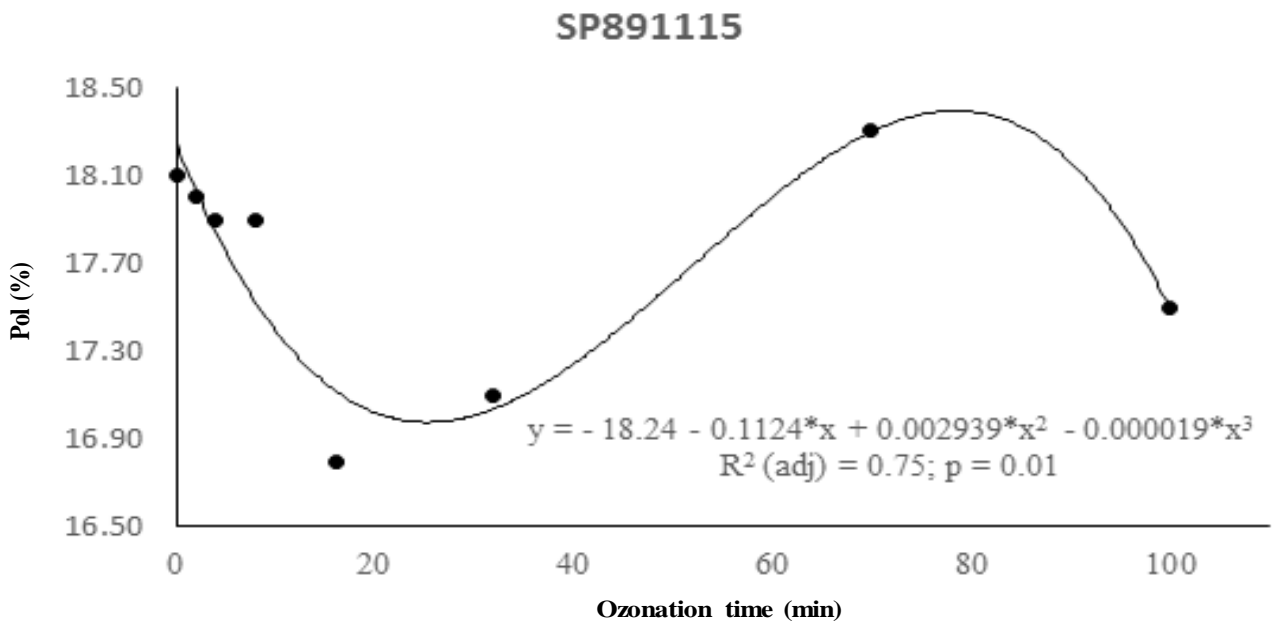

Figure 5. Regression analysis for Pol (\%) as a function of the ozonation time for the variety SP891115.

The values of Pol will affect sugar purity. Therefore, under the conditions of this study, the exposure interval between 32 and 70 min promoted a higher Pol (\%) for the juice of the variety SP 891115. In addition, for the juices of the varieties RB 867515 and RB 855453, no significant change ( $>0.05$ ) was observed at different times to ozone exposure, indicating no degradation and Pol values around the same average of $20 \%$.

In the analysis of total soluble solids (Brix) as a function of ozonation time, only the variety RB 867515 was adjusted to a significant regression model (R2adjusted $=0.79 ; \mathrm{p}=0.02$ ) (Figure 6). Thus, ozonation time did not affect the Brix contents of juices of the varieties SP 891115 and RB 855453 ( $>>0.05$ ). However, for the variety RB 867515 in the initial periods of up to 32 minutes of exposure, these contents decreased gradually tending to a stabilization after this period, which could be confirmed if the exposure time was higher (Figure 6).

\section{RB867515}

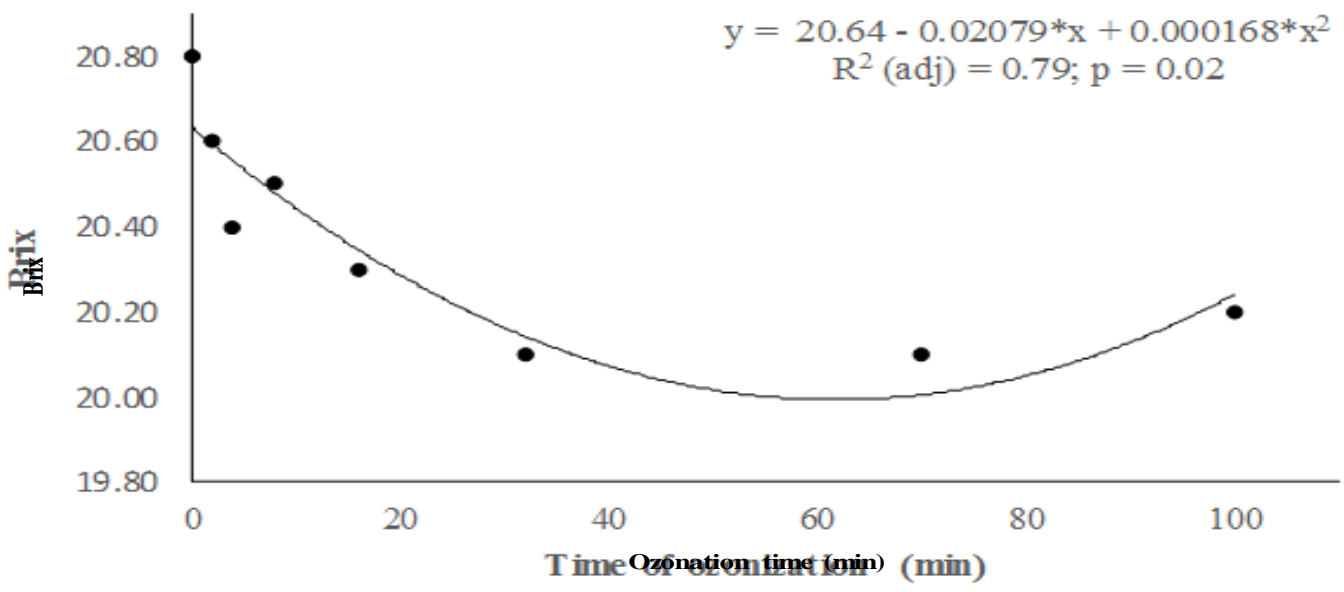

Figure 6. Regression analysis for the total soluble solids (Brix) as a function of the ozonation time for the variety RB867515.

\subsection{Interdependence relationship between varieties and ozonation time}

The characterization of a pattern or behavior depends on different interactions between the assessed factors. In this context, multivariate data analysis can be very efficient since it allows visualizing natural correlations and correlations of multiple influences on a behavior, especially when using multivariate techniques of interdependence, i.e. when no variable or group is treated as dependent or independent [13].

Figure 7 shows the biplot graph with the first two principal components (PC1 and PC2) as a function of the studied varieties. The variance assigned to them is shown in Table 2. For the variety RB 867515, PC1 and PC2 represented 64.1 and $21.3 \%$ of the total variance of the original data, respectively. The highest (95\%) and lowest $(82 \%)$ percentage of explanation were observed for the varieties RB $855453(\mathrm{PC} 1=63.1 \%$ and PC2 $=31.8 \%$ ) and SP 891115 (PC1 = 58.8\% and PC2 $=23.5 \%$ ), respectively. 

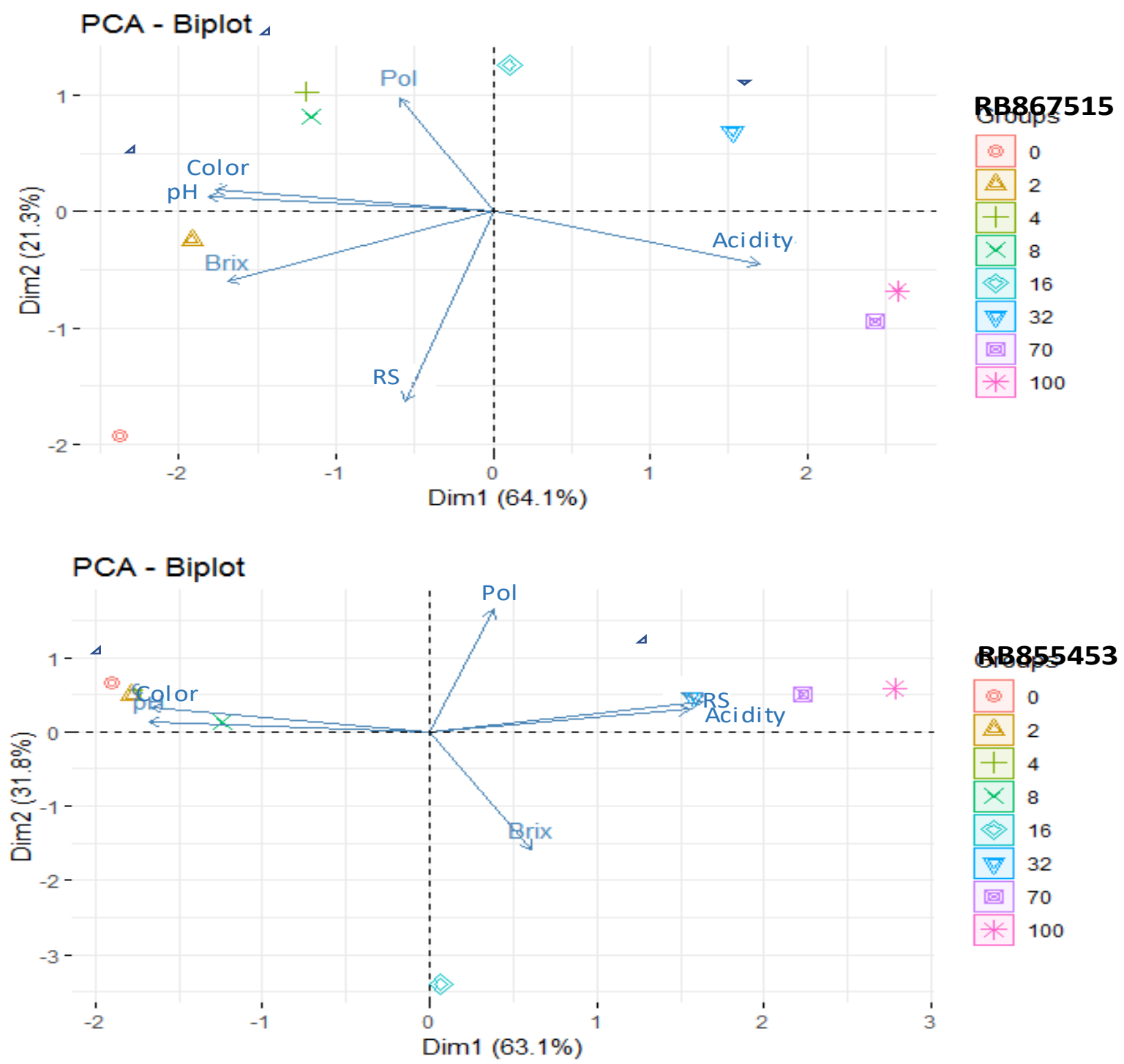

BB855453

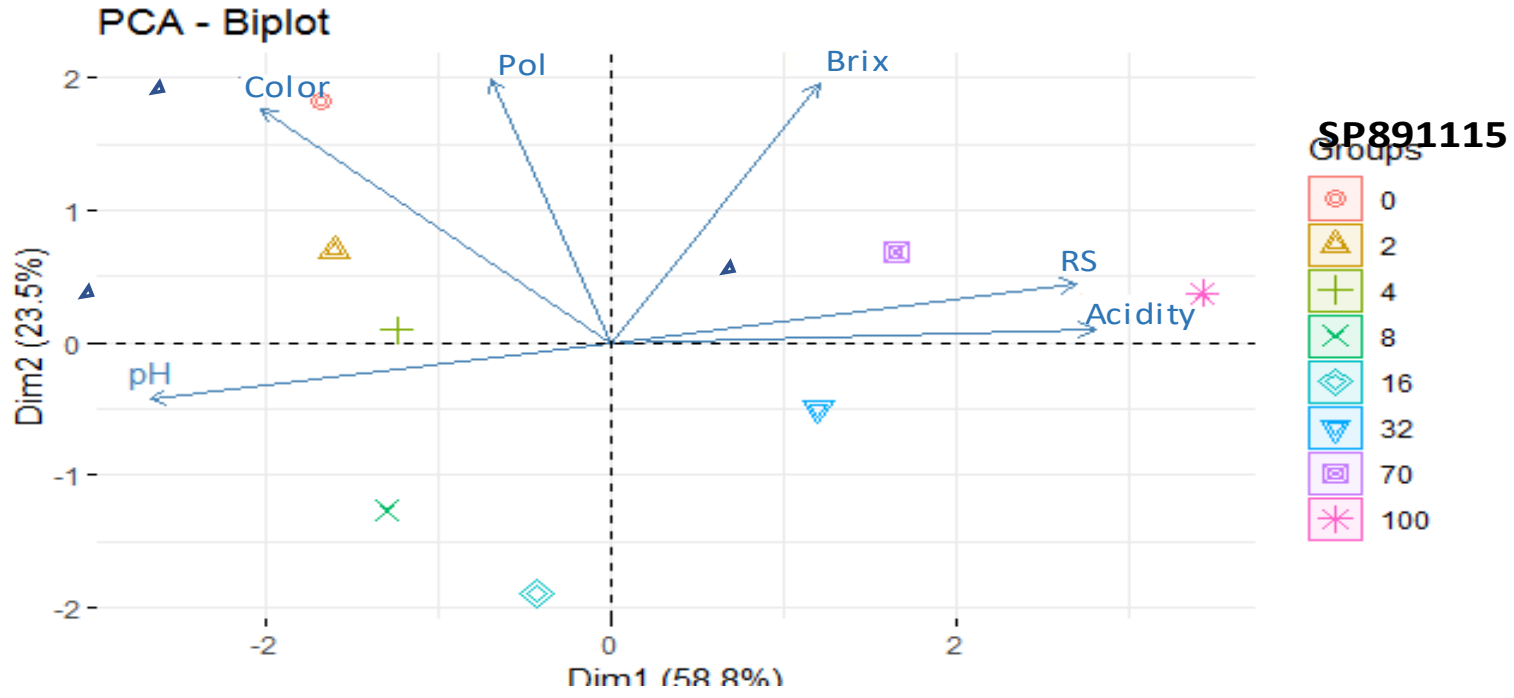

Figure 7. Biplot graph containing the physicochemical variables in the different ozonation times as a function of the varieties under study. 
Table 2. Correlation between variables and the first two principal components (PC1 and PC2) as a function of the varieties under study

\begin{tabular}{|c|c|c|}
\hline \multicolumn{3}{|c|}{ Variety RB867515 } \\
\hline Principal component & PC1 & PC2 \\
\hline Explained variance (\%) & 64.1* & 21.3* \\
\hline \multicolumn{3}{|l|}{ Correlation } \\
\hline $\mathrm{pH}$ & 0.99 & 0.07 \\
\hline Acidity & -0.93 & -0.25 \\
\hline Color & 0.97 & 0.10 \\
\hline RS & 0.31 & -0.90 \\
\hline Brix & 0.92 & -0.33 \\
\hline Pol & 0.33 & 0.54 \\
\hline \multicolumn{3}{|c|}{ Variety RB855453 } \\
\hline Principal component & PC1 & PC2 \\
\hline Explained variance (\%) & 63.1* & $31.8 *$ \\
\hline \multicolumn{3}{|l|}{ Correlation } \\
\hline $\mathrm{pH}$ & -0.98 & 0.08 \\
\hline Acidity & 0.95 & 0.23 \\
\hline Color & -0.97 & 0.20 \\
\hline RS & 0.91 & 0.18 \\
\hline Brix & 0.36 & -0.93 \\
\hline Pol & 0.22 & 0.96 \\
\hline \multicolumn{3}{|c|}{ Variety SP891115 } \\
\hline Principal component & PC1 & PC2 \\
\hline Explained variance (\%) & $58.8 *$ & $23.5 *$ \\
\hline \multicolumn{3}{|l|}{ Correlation } \\
\hline $\mathrm{pH}$ & 0.94 & 0.15 \\
\hline Acidity & -0.99 & -0.03 \\
\hline Color & 0.72 & -0.62 \\
\hline RS & -0.95 & -0.16 \\
\hline Brix & -0.43 & -0.69 \\
\hline Pol & 0.25 & -0.70 \\
\hline
\end{tabular}

*Value refers to the percentage of variation of the original set of data retained by the respective principal components. Correlations in bold ( $>0.50$ in absolute value) were considered in the interpretation of the principal component.

The variable acidity was associated with the highest ozonation times (32, 70, and 100) in the three assessed varieties. The variable RS was also more expressive in the highest ozonation times but for the varieties RB855453 and SP891115. On the other hand, the highest values of $\mathrm{pH}$ and color were associated with the lowest ozonation times in the three varieties.

In PC1, Brix (0.92), $\mathrm{pH}$ (0.99), and color (0.97) showed a direct dependence relationship from each other and inverse with acidity (-0.93) in relation to the juice of the variety RB 867515. The variables RS and Pol were retained in PC2. Considering that the components are orthogonal (not correlated), the processes retained in this component occur independently on the process in PC2. Thus, the relationships in PC1 do not depend on the relationships observed in PC2 (Table 2).

The varieties RB 855453 and SP 891115 presented a similar behavior in relation to the variables studied in the different ozonation times (Figure 1 and Table 2). Regarding the juices of these two varieties, $\mathrm{pH}$ and color are directly 
associated with each other and inversely associated with acidity and RS, which were retained in PC1.

In addition, the process contained in PC1 is the most important for this study, because it is derived from the highest eigenvalue and has the highest percentage of explanation. Thus, the variables that contributed the most to explain the juice characteristics as a function of the ozonation time in the three studied varieties were $\mathrm{pH}$, color, acidity, and air.

\section{Discussion}

The initial values of $\mathrm{pH}$ and acidity showed that the juices of the three sugarcane varieties were under appropriate conditions to be used in the industry and were obtained from healthy plants harvested in a timely manner and without deterioration (Figure 2a). According to Chen and Chou [15], sugarcane juice from healthy plants and at a full maturation stage is in the range of 5.2 to 5.4. On the other hand, after ozonation, a higher acidification was observed in the studied times. For instance, the juice of the variety RB 855453 had its $\mathrm{pH}$ reduced to 4 after 16 min of exposure and for 2.9 at 100 min of exposure (Figure 2a).

According to Chou et al. [16], $\mathrm{pH}$ values below 4.2 are indicative of sugarcane juice deterioration. In our study, from 32 min of exposure, the juice of the three varieties was already below the value referenced by those authors (Figure 2a). On the other hand, Silva et al. [7] assessed the ozonation effect on the sugarcane juice under two different conditions (heated and unheated juice) and observed that their $\mathrm{pH}$ remained practically constant as the color decreased gradually during the process.

In our study, juice color presented a significant decreasing effect as a function of the exposure time to ozone gas (Figure 3). Rein [17] also observed that juice ozonation promoted a decrease in the ICUMSA color index and that color removal was more significant in the first minutes of exposure to the gas.

The removal of the color of the sugarcane juice varies according to the crushing energy and variety, being influenced by chlorophyll, anthocyanin, and other chromogenic substances [11]. In addition, ozone dose and the purity and quantity of the coloring material also influence juice color, being the ozone very effective in the discoloration of sugarcane juice by attacking the double bonding of dyes, which are associated with color [7]. The use of ozone for the removal of juice color is not a recent technique. In this sense, Vercellotti and Clarke [18] already reported the use of this gas and its benefits not only in the reducing the color of the crystallized product but also in the molasses color after treatment.

Davis et al. [19] worked with solutions of sugar, syrup, and clarified sugarcane juice and reported that ozone showed to be an effective agent in the destruction of pigments and precursors of color. These authors determined that the use of $250 \mathrm{ppm}$ of ozone at temperatures of $70^{\circ} \mathrm{C}$ and $\mathrm{pH}$ between 6 and 7 was not only effective at reducing color but also color precursor pigments, such as amines and phenolic compounds, leading to a decrease in the color of the syrup by $33 \%$. Moodley et al. [20] tested the use of large-scale ozone at a sugar refinery in South Africa and reported the potential of using ozone for the process of decolorizing the syrup and obtaining the refined sugar.

In similar studies, Polívka et al. [21], Soja et al. [22], and Silva et al. [7] did not observe the effect of juice ozonation in relation to the content of reducing sugars (RS). Polívka et al. [21] found only a non-significant variation of $10.0 \%$ in RS. However, in our study, a significant effect was observed for the juices of the varieties RB 855453 and SP 891115, with a quadratic model adjusted for RB 855453 and a linear model for SP 891115 (Figure 4). This different behavior of sugarcane varieties as a function of RS observed in our study (Figure 4) was also reported by Larrahondo [24], who observed that the presence of phenolic compounds (major color promoters) varies according to crop management and varieties.

Apparently, this behavior can be explained by the high power of ozone, which promotes the oxidation of alcohols, leading to the obtaining of organic acids. Thus, the degradation of reducing sugars by ozone action in the group of alcohols of the molecules may have led to juice acidification (Figure 2b) since acid juices lead to sucrose inversion, generating reducing sugars that make sugar production unfeasible (Figure 3). According to Fonseca [11], the presence of reducing sugars, amino acids, and phenolic compounds is undesirable in white crystal sugar production processes, because they are color promoters. This effect is related to the indirect relationship between RS and color observed in our study (Figure 7 and Table 2).

The maintenance of the parameter Pol can be explained by the action of optically active organic acids. Thus, our study demonstrates that varietal factors are very important in the effect that ozonation can cause in the clarification of sugarcane juice. Varieties with a high content of antioxidant compounds (phenol, for example) will have these compounds degraded primarily and if the variety is poor in antioxidants, the degraded compounds will be the reducing sugars [23].

Because sugars are polyols, they can undergo oxidative degradation by ozone action, generating organic acids and a possible sucrose inversion. The presence of acids in the medium causes sucrose hydrolysis and therefore a decrease in Pol should occur. However, it did not occur in our study for the varieties RB 867515 and RB 855453 and for the variety SP 891115 (in the exposure period of 32 and $70 \mathrm{~min}$ ). Some organic acids are optically active and can overestimate the sucrose value when it is measured by means of the polarization of the solution under analysis. James et al. [25] reported 
the fragility of the $\alpha(\mapsto 2)$-glycosidic bond of sucrose, which is extremely sensitive to acidic conditions. Another disadvantage pointed out is its super-functionality, i.e. an excessive number of hydroxyls (eight) with similar reactivities. However, there are small differences of reactivities between primary and secondary hydroxyl groups, which have been exploited in acetylation, halogenation, and other reactions.

The difference in the composition of the sugarcane juice is one of the factors that affect the several unit operations of an industrial process, especially juice purification and, in the case of distilleries, the alcoholic fermentation [26]. Thus, maturation is one of the most important aspects of sugarcane crop in relation to the moment of industrialization, which is directly influenced by varieties, i.e. crop characteristics such as botany and physiology [24].

\section{Conclusion}

The physicochemical characteristics of the sugarcane juice are influenced by both the ozonation period and crop variety.

The variation in the Brix content of the sugarcane juice of the variety RB 867515 and the Pol (\%) of the variety SP 891115 occurs as a function of the ozonation time.

Ozonation time influences the $\mathrm{pH}$ and acidity of the sugarcane juice of the varieties RB 867515, RB 855453, and SP 891115. The ICUMSA color index of the sugarcane juice of the varieties RB 867515 and RB 855453 and the reducing sugar of the varieties RB 855453 and SP 891115 are also influenced by the exposure period since the ozone promotes the generation of organic acids by means of the degradation of reducing sugars, decreasing the $\mathrm{pH}$ and ICUMSA color and increasing the acidity of the medium.

For future studies, the ozonation period should be more fractioned and extended for a higher juice exposure to the gas in order to capture a more consistent behavior in relation to some physicochemical characteristics such as Pol (\%) and Brix.

\section{References}

[1] Conab. National Supply Company. (2018). Monitoring of the Brazilian harvest: sugar cane, third survey, 2017/18. https://www.conab.gov.br/info-agro/safras/cana.

[2] Morilla, C. H. G., Alves, L. R. A., and Aguiar, C. L. (2015). Process of clarification of sugarcane juice by sulfitation: commercial barriers of economic impacts. Economia em Revista, 24, 1-10. http://dx.doi.org/10.4025/aere.v24i1.24595.

[3] Sartori, J. A. S., Magri, N. T. C., and Aguiar, C. L. (2015). Clarification of sugarcane juice by hydrogen peroxide: effect of the presence of dextran. Braz. Journal of Food Science and Technology, 18, 299-306. http://dx.doi.org/10.1590/1981-6723.4215.

[4] Favero, D. M., Ribeiro, C. S. G., and Aquino, A. D. (2011). Sulphites: importance in the food industry and its possible harm to the population. Segurança Alimentar e Nutricional, 18, 1-20. http://dx.doi.org/10.20396/san.v18i1.8634684.

[5] Ferreira, F. S. (2015). Food additives and their adverse reactions in child consumption. Revista da Universidade Vale do Rio Verde, 13, 397-407.

[6] Silva, R. B., Wolquird, C. S., and Silva, F. S. (2008). Application of cleaner production in the process of clarifying sugarcane juice for sugar production. XXVIII National Meeting of Production Engineering. The integration of production chains with the sustainable manufacturing approach. Rio de Janeiro, Brazil.

[7] Silva, W. S., Sartori, J. A. S., and Aguiar, C. L. (2015). Combination effect of ozone and heat treatment for the color reduction in sugarcane juice. Chemical and Process Engineering Research, 35, 75-84.

[8] Fernandes, A. C. (2000). Calculations in the sugarcane agribusiness. STAB - Sugar, Alcohol and by-products, Piracicaba, Brazil.

[9] Franco, A. (2003). Sugarcane grown in soil fertilized with sewage sludge and vinasse: nitrogen in the soil-plant system, productivity and technological characteristics. Dissertation (Master in Agronomy). Faculdade de Ciências Agrárias e Veterinárias, Universidade Estadual Paulista, Jaboticabal, Brazil.

[10] Lopes, C. H. and Borges, M. T. M. R. (2012). Chemistry of sugar and alcohol processing. 2nd Edition. EDUFSCar, São Carlos, Brazil.

[11] Fonseca, C. R. (2017). Ozonização: uma alternativa para clarificação do caldo de cana-de-açúcar. PhD Thesis. Universidade de São Paulo, São Paulo, Brazil.

[12] Ridesa. Interuniversity Network for the Development of the Sugarcane Sector. (2015). 45 years of RB varieties of sugar cane: 25 years of Ridesa. http://socicana.com.br/2.0/wp-content/uploads/45-anos-variedades.pdf.

[13] Copersucar. Cooperativa Brasileira de Açúcar e Álcool. (2015). Agronomic characteristics of varieties. http://www.gestaonocampo.com.br/biblioteca/caracteristicas-agronomi cas-das-variedades-sp.

[14] Hair, J. F., Black, W. C., Babin, B. J., Anderson, R. E., and Tatham, R. L. (2005). Mutivariate date analysis. 5th Edition. Bookman, Porto Alegre, Brazil.

[15] Kaiser, H. F. (1958). The varimax criterion for analytic rotation in factor analysis. Psychometrika, 23, 187-200. http://dx.doi.org/10.1007/BF02289233. 
[16] Chen, J. C. P. and Chou, C. (1993). Cane Sugar Handbook: a manual for cane sugar manufacturers and their chemists. 12th Edition. John Wiley \& Sons, New York, USA.

[17] Chou, C. C., Iqbal, K., Min, Y. G., Gao, D. W., and Duffaut, E. (2006). SAT Process as a replacement for sulfitation in mill white sugar production. International Sugar Journal, 108, 247-253.

[18] Rein, P. (2007). Cane sugar engineering. Verlag Dr. Albert Bartens KG, Berlin, Germany.

[19] Vercellotti J. R. and Clarke, M. A. (1997). Color removal—chemical treatment. Sugar Processing Research Institute, 56, 272-281.

[20] Davis, S. B., Moodley, M., Singh, I., and Adendorff, N. W. (1998). The use of ozone for colour removal at the Malelane refinery. South African Sugarcane Research Institute, 72, 255-260.

[21] Moodley, M., Davis, S. B., and Abendorff, M. (1999). Full Scale decolourisation trials with ozone. International Sugar Journal, 101, 165-170.

[22] Polívka, L., Fendric, E., and Skarka, B. (2002). Influence of ozone on properties of jams. Czech Journal of Food Sciences, 20, 113-115.

[23] Soja, G., Reichenauer, T. G., Eid, M., Soja, A.-M., Schaber, R., and Gangl, H. (2004). Long-term ozone exposure and ozone uptake of grapevines in open-top chambers. 2004. Atmospheric Environment, 38, $2313-232$. http://dx.doi.org/10.1016/j.atmosenv.2003.12.038.

[24] Larrahondo, J. E. (1995). Sugarcane quality. In: Cassalett, C., Torres, J., Isaacs, C. Eds., The cultivation of the sugar cane in the sugar zone of Colombia. Research Center of Sugar Cane of Colombia, Calle, Colombia, 337-354.

[25] James, C. E., Hough, L., and Khan, R. (1989). Sucrose and its derivatives. Progress in the Chemistry of Organic Natural Products, 55, 117-184.

[26] Cesar, M. A., Delgado, A. A., Camargo, A. P., Bissoli, B. M. A., and Silva, F. C. (1987). Capacity of natural and artificial phosphates to increase the content of phosphorus in the sugarcane juice (cane-plant), aiming at the industrial process. STAB: Açúcar, Álcool e Subprodutos, 6, 32-38. 